\title{
Anthony J. Burke ChemPubSoc Europe Fellow 2018/2019
}

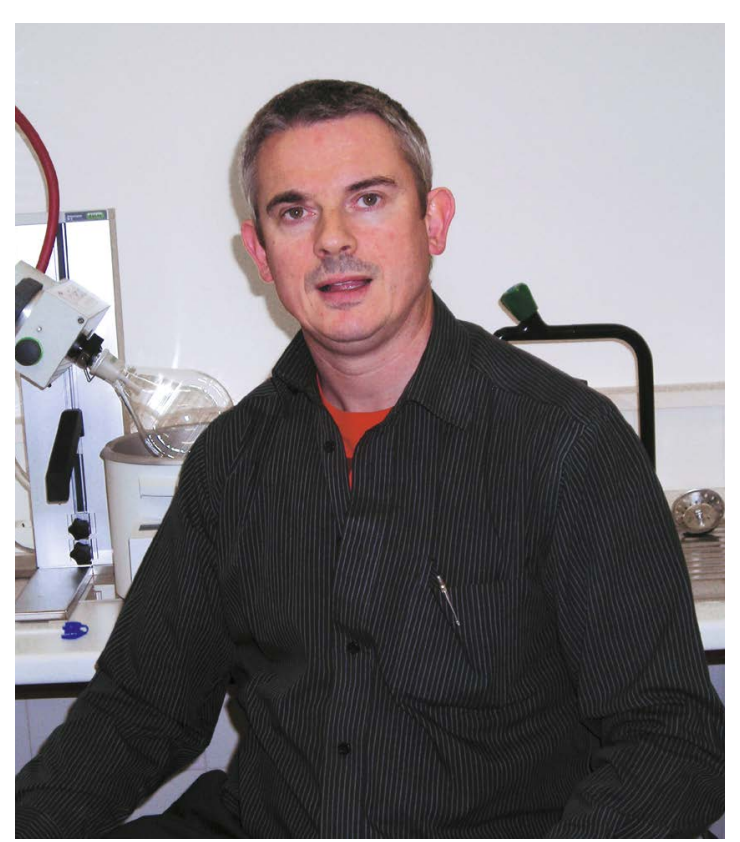

Anthony J. Burke ajb@uevora.pt

Anthony J. Burke é Doutorado em Química pela University College Dublin, tendo feito pós-doutoramento na Universidade de Oxford (com Steve Davies) e no Instituto de Tecnologia Química e Biológica António Xavier (com Chris Maycock). É Professor Associado com Agregação do Departamento de Química da Universidade de Évora, membro integrado do centro de investigação LAQV-REQUIMTEUniversidade de Évora e ChemPubSoc Europe Fellow desde 2020. Possui mais de 130 trabalhos (incluindo livros, capítulos de livros, artigos, patentes, editoriais e apresentações orais) e coordenou vários projetos, entre os quais um projeto atual de desenvolvimento de hidrogéis para promover a cicatrização

\author{
Interação Química com \\ Maria José Lourenço \\ Paulo Mendes \\ mjlourenco@ciencias.ulisboa.pt \\ pjgm@uevora.pt
}

\begin{abstract}
Esta Interação Química vem no seguimento da atribuição da distinção ChemPubSoc Europe Fellow Class 2018/2019, em 2020, ao colega e sócio n. ${ }^{\circ}$ 4097 da SPQ Anthony J. Burke, do Departamento de Química da Universidade de Évora. O programa Fellows of ChemPubSoc Europe tem como objetivo reconhecer o contributo significativo e grau de compromisso na divulgação da atividade científica através das publicações do consórcio ChemPubSoc Europe e pelo serviço exemplar a, no mínimo, uma das sociedades, premiando o desempenho por serviços que em geral não são reconhecidos.
\end{abstract}

de feridas em cães. Obteve sucesso na descoberta de moléculas com potencial aplicação no tratamento da doença de Alzheimer e do cancro e tem um grande interesse em processos catalíticos sustentáveis. Outras áreas de interesse incluem semicondutores e dispositivos optoeletrónicos, síntese de polímeros e RMN. Orientou mais de 70 alunos (pósdoutoramento, doutoramento, mestrado e licenciatura). Foi Vice-Presidente da Divisão de Química Orgânica da Sociedade Portuguesa de Química (SPQ) no período 2011-2013. Fundou a empresa Chiratecnics (chiratecnics.com) em 2009 e é chairman da série de conferências International Symposium on Synthesis and Catalysis. Atualmente é editor da Open Chemistry (De Gruyter). 
Parabéns pela distinção Chemistry Europe Fellow Class 2018/2019. Que significado tem este reconhecimento para si? Como é que este mérito contribui para o desenvolvimento do seu trabalho?

É uma honra e um privilégio receber este prémio, e estar incluído entre tantos outros colegas ilustres em toda a Europa. Também gostaria de aproveitar esta oportunidade para agradecer oficialmente a todos os meus alunos e colaboradores, cuja contribuição nas últimas duas décadas tornou possível este reconhecimento. Este importante prémio irá contribuir de forma significativa para a minha carreira, bem como para as atividades de investigação do meu grupo em Évora. Irá certamente atrair muita atenção sobre mim e o meu grupo, mas também sobre o meu departamento, o centro de investigação e a universidade onde estou inserido. Espero que nos permita divulgar o nosso trabalho a um público mais amplo e que sejamos ainda mais pró-ativos junto da comunidade química europeia, contribuindo ainda mais para o seu avanço e evolução.

Recorda-se do seu primeiro contacto com o que hoje se chama Chemistry Europe ou com alguma das suas secções?

$\mathrm{Sim}$, o meu primeiro contacto com a Chemistry Europe foi em 2009, quando publicámos um artigo sobre alquilações alílicas assimétricas catalisadas por paládio. Nesta reação estudámos o ligando difosfina DuPhos. Foram alcançadas excelentes enantiosseletividades, tendo sido demonstrada a versatilidade desta

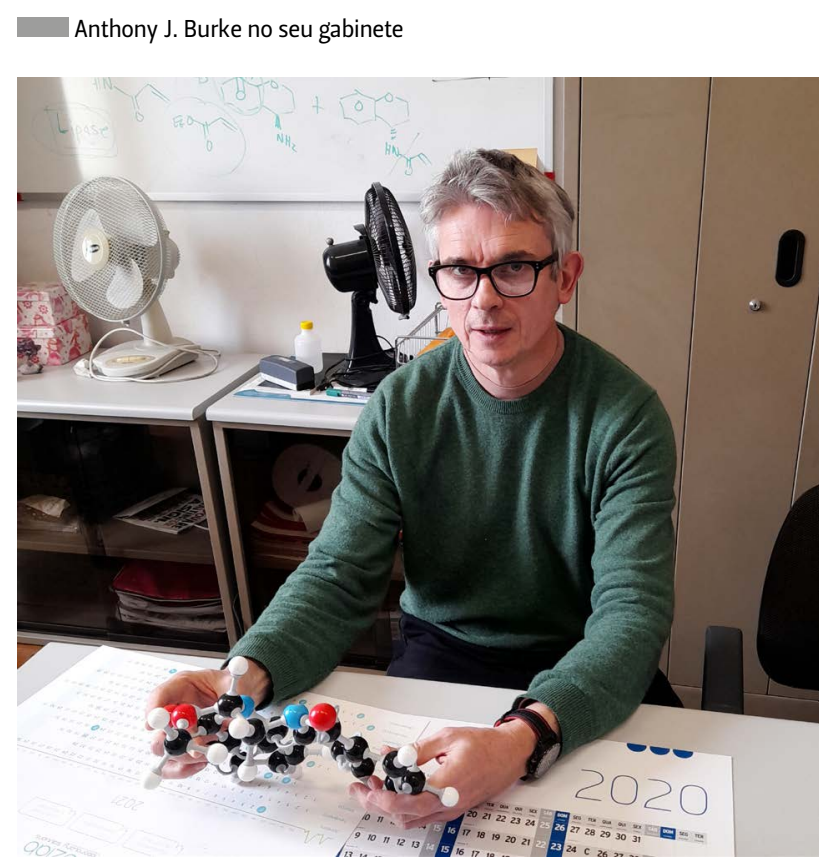

fosfina comercial em catálise assimétrica. Também apresentámos um estudo computacional detalhado para explicar o mecanismo e a regiosseletividade da reação. Desde essa altura esta relação foi-se fortalecendo cada vez mais.

66

Tenho uma vasta experiência com as publicações do consórcio Chemistry Europe, principalmente como autor, revisor e editor convidado. A experiência foi muito positiva.

Tem alguma experiência com os periódicos da Chemistry Europe? Como foi essa experiência?

Tenho uma vasta experiência com as publicações do consórcio Chemistry Europe, principalmente como autor, revisor e editor convidado. A experiência foi muito positiva. Já trabalhei com diversos editores - sempre mostrando grande profissionalismo - e a experiência é sempre gratificante.

O periódico Chemistry - A European Journal iniciou a sua publicação há 25 anos e a ChemistryViews Magazine há 10 anos. Qual a sua ideia sobre o futuro da Chemistry Europe? Porquê?

Eu sugeriria que a Chemistry Europe organizasse várias conferências cientíicas especializadas, semeIhantes às conferências da Tetrahedron (Elsevier), concentrando-se em vários aspetos da química, desde a síntese química à química medicinal, da eletroquímica e química-física à química verde, entre outras. No contexto da atual pandemia COVID-19, existe a oportunidade para que se organizem em formato digital. A Chemistry Europe poderia também patrocinar bolsas de doutoramento para os alunos europeus mais talentosos, bem como patrocinar vários prémios anuais para os melhores investigadores nas áreas de maior importância. 
Tem alguma experiência com o Química, o Boletim da Sociedade Portuguesa de Química? Que significado tem esta publicação para si e quais são os aspetos mais relevantes?

Eu tenho uma boa experiência com esta publicação, já tive a oportunidade de publicar no Química e conheço muito bem os editores. Para além da publicação de notícias sobre vários eventos com impacto na comunidade científica portuguesa, homenagens, entrevistas e artigos de natureza muito geral e atual, realço a secção das atualidades científicas com o destaque (highlights) de desenvolvimentos químicos significativos a nível internacional e a recente disponibilização online, de forma antecipada, dos artigos já aceites para publicação.

Tem alguma sugestão para melhorar a qualidade e a visibilidade do Química e tornar esta publicação mais apelativa aos leitores?

Com o novo formato da revista e a disponibilização online dos artigos aceites para publicação, além de artigos de revisão, acho que esta revista poderia considerar a publicação de trabalhos de investigação originais, provavelmente em inglês (com resumo em português) para atrair um público nacional e internacional. Além disso, atrairia certamente muita atenção da comunidade de químicos portugueses, em particular os jovens investigadores, e também de investigadores da Europa e de outros países. As publicações poderiam ser mais frequentes, com edições mensais, por exemplo. Poderia estabelecer-se um conselho editorial internacional para garantir a publicação de artigos de elevada qualidade. Seria certamente uma grande oportunidade para a comunidade dos químicos portugueses.
Qual é a sua opinião sobre a Sociedade Portuguesa de Química (SPQ) e da sua importância na rede das Sociedades Europeias de Química?

A SPQ é uma instituição de apoio à Química a nível nacional. A SPQ apoia vivamente todos os aspetos da atividade química em Portugal, desde a pesquisa, ao ensino, passando pela disseminação/divulgaç̧ão científica e muito mais. A SPQ é uma componente muito importante da rede europeia de sociedades químicas, e que representa as vozes da comunidade química portuguesa. A química em Portugal tem vindo a ganhar força nos últimos 20 a 25 anos, traduzida pelo número signnificativo quer de publicações importantes quer pelo número de projetos europeus e internacionais que envolvem investigadores portugueses.

Que medidas se devem implementar para melhorar a SPQ? Que iniciativas devem ser apoiadas?

No ano passado, a SPQ apoiou a investigação de jovens químicos, atribuindo bolsas de doutoramento aos alunos mais talentosos. Eu acho que esta iniciativa deve continuar, com concursos anuais apoiados pela SPQ. A SPQ também atribui prémios aos melhores jovens investigadores (bem como prémios para os investigadores mais seniores) em áreas específicas da química, bem como prémios às melhores teses de doutoramento e de mestrado, e deve continuar a fazê-lo. A indústria química portuguesa é pequena em comparação com a de outros países europeus, mas apesar disso, talvez pudesse haver uma maior interação com essas empresas, talvez usando o Química como um catalisador ou linker (para usar dois bons termos químicos). No contexto da indústria, existe já um vasto ecossistema de novas start-ups a desenvolver-se aqui em Portugal, muitas das quais exploram produtos químicos ou conhecimento químico. A SPQ pode considerar a interação com essas entidades em certos contextos e, novamente, o Química poderia ser usado como um "trampolim" para promover boas relações e iniciativas.

Quais são os seus interesses científicos atuais? Quais são os aspetos e os benefícios mais relevantes para a sociedade que a sua investigação pode produzir?

Os meus interesses de investigáção diversificaram-se nos últimos 20 anos. Nos primeiros 10 anos, o meu grupo focou-se na síntese orgânica, na catálise, na imobilização de catalisadores e na catálise assimétrica. Porém, nos últimos 10 anos, temo-nos interessado cada vez mais nas aplicações deste trabalho e em como poderão beneficiar a sociedade. Estamos mais focados na saúde e na segurança alimentar, onde usamos a nossa extensa experiência química: a) no desenvolvimento 
de novas moléculas para o tratamento de doenças neurodegenerativas e cancro; b) no desenvolvimento de novos materiais poliméricos para análise de pesticidas em azeite; c) nas técnicas de RMN para distinguir variedades de azeite, particularmente no contexto da adulteração deste produto. Os nossos interesses atuais incluem também o design e o desenvolvimento de novos materiais optoeletrónicos, novos materiais para a captação de água e a investigação na área de reciclagem de materiais plásticos.

\section{6}

\section{Seria fantástico se} pudéssemos desenvolver uma nova molécula com impacto no tratamento do cancro ou da doença de Alzheimer.

\begin{abstract}
Que descobertas/avanços científicos gostaria de anunciar nos próximos 5 a 10 anos?

Seria fantástico se pudéssemos desenvolver uma nova molécula com impacto no tratamento do cancro ou da doença de Alzheimer. Ainda estamos a trabalhar nessas áreas, e quem sabe? Ao mesmo tempo, gostaríamos de fazer avanços no campo de materiais eletrónicos orgânicos, leves e estáveis, e outros sistemas com aplicações diretas na sociedade. Talvez pudéssemos desenvolver novos catalisadores químicos que possam mostrar o mesmo nível de eficiência e elegância das enzimas.
\end{abstract}

\section{Além da sua investigação também está envolvido noutras atividades. Gostaria de fazer uma breve referência a essas atividades e à satisfação pessoal que obtém com cada uma delas?}

Ter a possibilidade de dar aulas aos alunos do primeiro, segundo e terceiro ciclos do ensino superior é altamente gratificante. Permite-me melhorar as minhas competências de comunicação e ao mesmo tempo estimular e motivar os alunos para esta área do

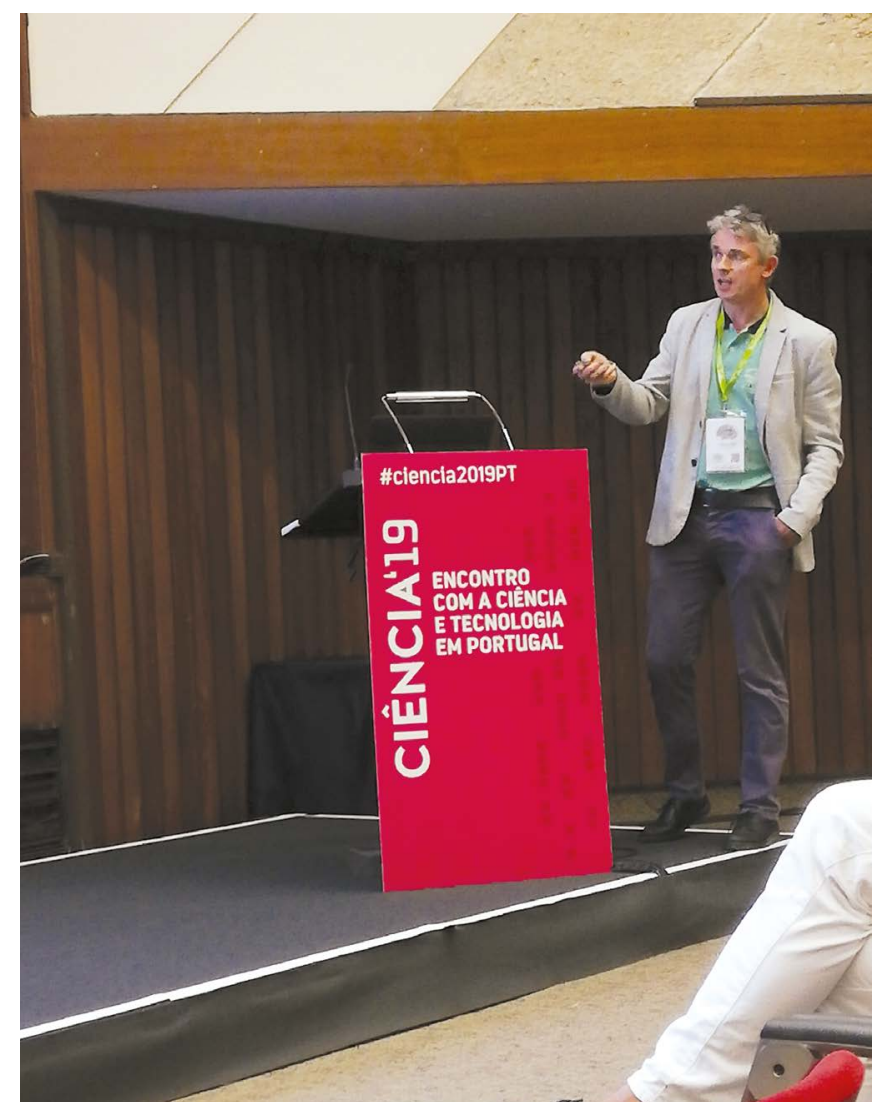

Anthony J. Burke numa das suas comunicações

conhecimento. Também fundei a empresa Chiratecnics (chiratecnics.com) há 10 anos, para comercializar a propriedade intelectual desenvolvida na minha Universidade e para desenvolver produtos para clientes das indústrias farmacêutica e química. Esta tem sido uma grande experiência, permitindo-me entender as necessidades e o modus operandi da indústria, muito diferentes da academia. Sou chairman da série de conferências International Symposium on

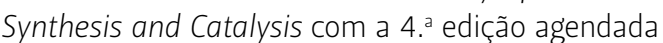
para setembro de 2021. Essas conferências são muito bem-sucedidas, tanto a nível profissional como social, trazendo-me muita satisfação pessoal. Esperamos que a série possa continuar indefinidamente. Também sou um dos editores da Open Chemistry (De Gruyter) e todos os anos faço a revisão de alguns artigos para diferentes editoras. A satisfação pessoal que este trabalho me dá está relacionada com o facto de poder ajudar os autores a exporem os seus trabalhos e serem reconhecidos pelos seus pares.

Muito obrigado pelo tempo que nos cedeu para esta Interação Química. 